\title{
Reclamation of the illegal dump for sustainable development the environment in Sverdlovo of Leningrad Oblast', Russia
}

\author{
Maria Bukova ${ }^{1, *}$, Andrey Bondal ${ }^{1}$, Olga Skvortsova ${ }^{1}$, Olga Nikonova ${ }^{1}$, Artem \\ Kholodiakov ${ }^{1}$, Inna Guseva ${ }^{1}$, Tatiana Makarova ${ }^{1}$, and Wilfried Mirschel $^{2}$ \\ ${ }^{1}$ Peter the Great St. Petersburg Polytechnic University, 195251 Polytechnicheskaya str. 29, \\ St. Petersburg, Russia \\ ${ }^{2}$ Leibniz-Centre for Agricultural Landscape Research, 15374 Eberswalder Straße 84,Müncheberg, \\ Germany
}

\begin{abstract}
Illegal dumping is dumping of any waste such as oil, furniture, appliances, trash, litter or landscaping cuttings, upon any land of state, city, village or private ownership without consent of the owner. Illegal dumping has a great negative and fatal impact on our environment and all living organisms both fauna and flora. It also exposes people to various risks of chemicals (fluids or dust) and is a big threat to all under-ground and surface water resources. Illegal dumps also attract all kinds of bugs such as rodents and insects. For example, illegal dumps with waste tires provide a practically perfect place for mosquitoes to breed. Mosquitoes can multiply 100 times faster than normal in the warm, stagnant water in waste tires. Exemplary for the illegal dump in Sverdlovo of Leningrad Oblast' the main purpose of this article is to offer a possible option for the remediation of contaminated area.
\end{abstract}

\section{Introduction}

Nowadays ecological situation in Sverdlovo, which is situated in Vyborgsky District of Leningrad Oblast', is deteriorating because of the dump, which has illegally appeared there. Earlier, when this territory was clean, there were some clay pits, where people got clay for brick production. The clay pits appeared there at the beginning of the XIX centaury, and during the 200 years after establishing, they were filling up with water. Landscape, which had transformed due to the clay-extraction, turned to the recreation area for many people. Unfortunately, the territory has recently become operating as an illegal dump: it is filling up with construction and household wastes (Fig. 1).

The relevance of cleaning the territory is obvious, because the dump has significantly deteriorated the environment and the surrounding area. Today we can verify harmful gases $\left(\mathrm{CH}_{4}, \mathrm{CO}_{2}\right)$ from the decomposition of organic wastes and an increasing number of rodents and insects. Periodic burning of the landfill pollutes the atmosphere with toxic substances. In addition, it has a harmful impact on the quality of the nearby ponds and streams. The

* Corresponding author: miss-kant@yandex.ru 
water research, which was conducted by members of the FBU «Center of laboratory analysis and technical measurements», revealed the presence of a high content of phenol, iron and oil products [1].

The main purpose of this article is to offer a possible option for the remediation of contaminated areas. As the state of the environment at the place of the dump becomes environmentally dangerous, it is necessary to carry out measures to restore the favorable ecological situation in this area.

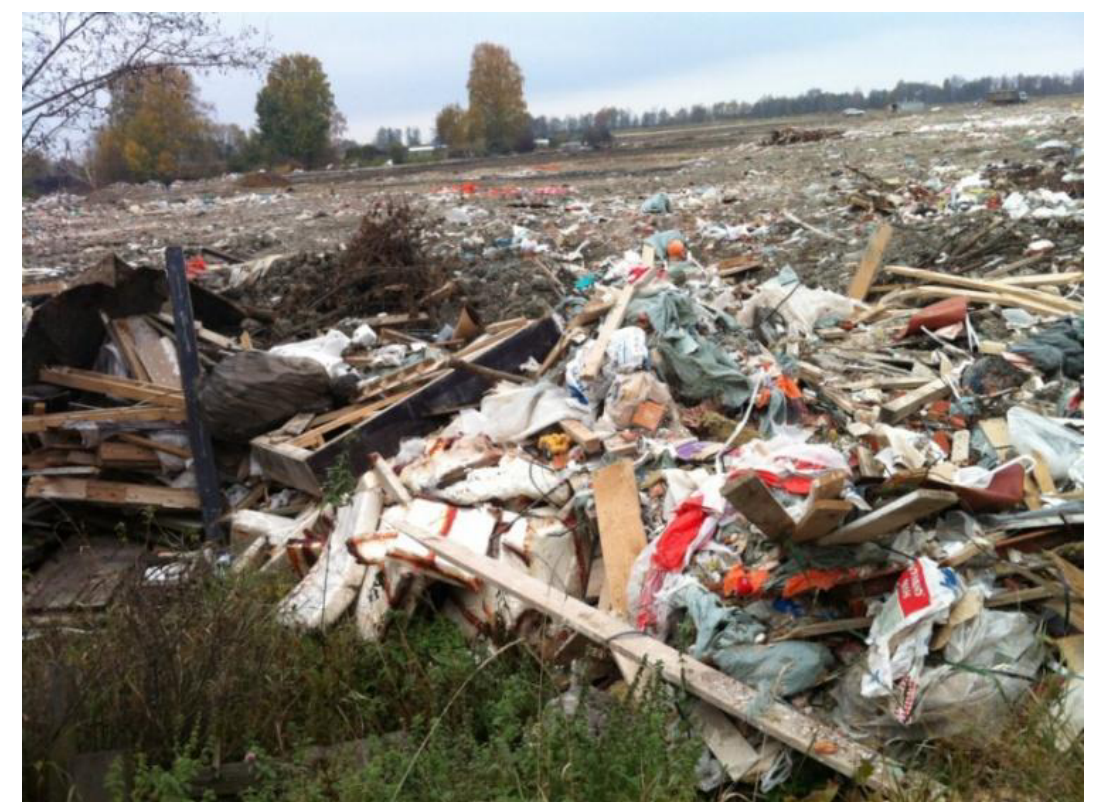

Fig. 1. Illegal dump in Sverdlovo of Leningrad Oblast', Russia.

\section{Problem of urgency concerning illegal dumpsite}

A dumpsite (also tip, landfill, rubbish dump, garbage dump or dumping ground) is a site for the disposal of waste materials by burial and is the oldest form of waste treatment [2]. Historically landfills have been the most common method of waste disposal organization. Moreover, they remain so in many countries around the world. Some dumps are also used for waste management purposes, such as the temporary storage, consolidation and transfer, or processing of waste material (sorting, treatment, or recycling). A dump also may refer to ground that has been filled in with rocks instead of waste materials, so that it can be used for a specific purpose, such as for building houses. Unless they are stabilized, these areas may experience severe shaking or liquefaction of the ground during an intensive earthquake.

Dumpsites have the possible potential to cause a number of issues. Infrastructure disruption, such as damage to access roads by heavy vehicles, may occur. Pollution of local roads and water courses from wheels on vehicles when they leave the dumpsite can be significant. Pollution of the local environment, such as contamination of groundwater or water horizon or soil pollution may occur, as well. Extensive efforts are made to capture and treat leachate from landfills before it reaches groundwater horizon, but engineered liners always have a lifespan, though it may be 100 years or more. Eventually, every dumpsite liner will leak, allowing the leachate to contaminate the groundwater [3]. 
Methane is naturally generated by decaying organic wastes in a dump or landfill. It is a potential greenhouse gas which can destroy the atmospheric ozone, and can itself be a risk or danger because it is flammable and potentially explosive. In properly managed landfills, gas is collected and utilized. This could range from simple flaring to landfill gas utilization [4]. Poorly run dumpsites may become nuisances because of vectors such as rats and flies which can cause infectious diseases. The occurrence of such vectors can be mitigated through the use of daily cover. Other potential issues include wildlife disruption, dust, odor, noise pollution, and reduced local property values.

\section{Method and proposed solutions}

The method for land reclamation described here, are implemented in three stages: preparatory, technical and biological.

\subsection{Preparatory stage}

At the preparatory stage, scientists are exploring the disturbed areas and determine the direction of reclamation. The major activities of mechanical cleaning of territories and removal of surface contamination are carried out before the technical stage. The preparatory phase of the water (drainage and water barrage) facilities construction involves a preliminary assessment of the hydrological conditions of the recultivated object.

Indicators of soil hydrophysical properties: water-retention capacity and hydraulic conductivity of the soil are among the important indicators that characterize the hydrological conditions of recultivated lands. It is necessary to conduct soil-reclamation engineering research in order to receive these indicators. As part of these investigations appropriate laboratory studies are carried out. These studies are very time- and labourconsuming. Using the technology of indirect estimation of indicators of soil hydrophysical properties with respect to the available data is advisable to reduce the costs of carrying out soil-reclamation research. For example, the water-retention capacity of the soil can be estimated using so-called soil hydrological constants, such as Field Capacity and Wilting Point [5], and applying pedotransfer functions [6].

Hydraulic conductivity of the soil can be assessed using an improved method of Mualem-Van-Genuchten [7-10]. The method based on the fact that the water-retention capacity and soil hydraulic conductivity are described by mathematical functions with a single set of parameters. Physical interpretation is proposed for these parameters. This interpretation is based on the idea of the soil as a capillary-porous media. In accordance with these representations distribution of soil pores by its size obeys a lognormal distribution [11-14]. The value of the capillary pressure (capillary-sorption potential) of the soil moisture $\psi\left[\mathrm{cm} \mathrm{H}_{2} \mathrm{O}\right.$ ] is used to describe the interaction of water with the surface of the soil particles. The volumetric water content $\theta\left[\mathrm{cm}^{3} \cdot \mathrm{cm}^{-3}\right]$ is used to describe the moisture content of the soil. Function $\theta(\psi)$ describes WRC (water-retention capacity) of the soil as:

$$
\theta=\left[\begin{array}{l}
\theta_{r}+\left(\theta_{s}-\theta_{r}\right)(1 / 2) \operatorname{erfc}\left\{(n \sqrt{\pi} / 4) \ln \left[-\alpha\left(\psi-\psi_{a e}\right)\right]\right\}, \psi<\psi_{a e} \\
\theta_{s}, \psi \geq \psi_{a e} ;
\end{array}\right.
$$

where: $\theta_{s}$ is volumetric saturated soil water content; $\theta_{r}$ is volumetric residual soil water content; $\psi_{a e}=-\beta / r_{\max }$ is bubbling pressure; $\alpha=r_{\text {max }} \boldsymbol{r}_{\mathbf{0}} / \beta$ and $n=4 /(\sigma \sqrt{2 \pi})$ are position and shape parameters respectively (further explanation: $\boldsymbol{r}_{\mathbf{0}}=r_{0} /\left(r_{\max }-r_{0}\right) ; \sigma$ is standard deviation of random variable $\ln \boldsymbol{r} ; \boldsymbol{r}_{\mathbf{0}}$ is pore radius that corresponds to the most 
probable value $\ln \boldsymbol{r}_{\mathbf{0}}$ of random variable $\ln \boldsymbol{r} ; \boldsymbol{r}=\left(r-r_{\min }\right) /\left(r_{\max }-r\right) ; r$ is pore radius; $r_{\min }$ is radius of the smallest pore; $r_{\max }$ is radius of the largest pore; $\beta=2 \gamma \cos \varphi /\left(g \rho_{\mathrm{w}}\right)$ is coefficient of proportionality; $\gamma$ is measure the surface tension of soil moisture; $\varphi$ is angle of the contact of the surface of soil particles; $g$ is gravity acceleration, $\rho_{w}$ is density of liquid water).

Hydraulic soil conductivity is described as following:

$$
k=\left[\begin{array}{l}
\left.k_{\mathrm{s}} \sqrt{\operatorname{erfc}\left\{(n \sqrt{\pi} / 4) \ln \left[-\alpha\left(\psi-\psi_{a e}\right)\right]\right.}\right\}\left(\operatorname{erfc}\left\{(n \sqrt{\pi} / 4) \ln \left[-\alpha\left(\psi-\psi_{a e}\right)\right]+2 /(n \sqrt{\pi})\right\}\right)^{2} /(4 \sqrt{2}), \\
k_{\mathrm{S}}, \psi \geq \psi_{a e},
\end{array}\right.
$$

where $k_{s}$ - coefficient of filtration of soil moisture.

\subsection{Technical stage}

Technical stage includes the planning, the installation of hydraulic and drainage structures, the covering potentially fertile soil layer and other works, which establish necessary conditions for further use of the land for the intended purpose. The technical stage has several steps and may include an intermediate step - chemical remediation.

The first step involves the selective mining, storage fertile soil layer and non-toxic species, which will be used after finishing the work. The second stage includes the planning and formation of the surface area. Pits, quarries and ravines are used for mounds, with the creation of a relief in accordance with the sanitary standards of the chemical and mineralogical composition of stored rocks. The third stage involves works on the formation of the potentially fertile soil layer for the subsequent stage of the biological remediation.

Formation of the root zone depends on their rocks; if they contain more than $20 \%$ of toxic compounds, chemical reclamation is carried out; then a layer of parent rock and on top of the root zone - potentially fertile layer. At the same stage, there are works to protect areas from storms and flood waters, water and wind erosions. These works include construction of drainage and water protective structures [15].

After the completion of the technical stage of recultivation biological stage occurs, whose task is to improve the properties of the soil. During this stage the physical and chemical properties of formed soils should be taken into account. The soil may be fertilized or sowed tree strengthen mixtures for fixing the surface layer of soil to prevent erosion, if it is necessary.

\subsection{Biological stage}

The biological reclamation stage includes a set of agronomic and phyto-reclamation activities using different bioremediation techniques [15]. Agrotechnical activities contribute to the creation of soils with favorable for the development of plant properties and include:

- loosening the soil to accelerate the physical, chemical and biochemical processes;

- creation of an artificial micro-relief, which is made of alternating grooves and mounds on soils with excess moisture;

- implementation of necessary fertilizers.

Recultivated soil and the surrounding area must be ecologically balanced sustainable landscape after the completion of all works. According to the instructions of land reclamation [16], connected with hygiene, the following requirements must be complied: 
- a choice of means preserving disturbed land, which depends on the condition, composition and properties of rocks, weather conditions, technical and economic indicators;

- activities for technical and biological reclamation disturbed lands with preserving, are agreed in accordance with the sanitary and epidemiological service;

- the use of binding materials for fixing the surface of disturbed lands, that do not have a negative impact on the environment and have sufficient water resistance and resistance to temperature fluctuations;

- covering a shielding layer of soil from the potentially fertile soils on the surface of industrial mounds, made of unsuitable for biological remediation substrate;

- implementation of land reclamation;

- conservation of the tailings, slurry tanks, ash dumps and industrial waste dumps containing toxic substances;

- fixing the industrial waste dumps using technical, biological and chemical methods.

The phytoremediation method is used to cleanse the area from harmful gases. The method is based on the ability of plants to absorb different compounds, split them and use as a food. Using the method of phytoremediation, territories become cleaner from many kinds of pollution, including the salts of heavy metals, pesticides and petroleum hydrocarbons. Moreover, plants prevent the transfer of pollutants from the soil surface, contaminated sites in water ecosystems and other environmental components [17, 18]. As a result, after preparatory and technical works on the reclamation, it is needed to use plants that are typical for the Sverdlovo region: red clover, timothy grass, meadow fescue, white clover.

\section{Results and discussions}

The mathematical model of soil hydrophysical properties mentioned above is used in the following way. The first step is to measure the dependence $\theta(\psi)$ or to assess this relationship using soil hydrological constants. Further, using the measured data $\theta(\psi)$ the hydrophysical parameters of the functions (1) and (2) can be defined. The second step is to measure the ratio $k_{s}$ and then calculate the values of the hydraulic conductivity of the soil. Hydrophysical functions (1) and (2) with estimated parameters could be used in calculations of soil moisture dynamics [19-22].

These calculations allow taking reasonable engineering solutions during the development of measures for land reclamation, as well as the design of reclamation systems. If reclamated lands, which are very important to protect [23, 24], involved in agricultural use, so the calculations of the soil moisture dynamics are relevant during the forecasting of crop yields [25-29].

Further, the other stages of reclamation are realized, with strict adherence to the instructions. It is also important to implement individual approach to every case of described issue. It is necessary to calculate correctly the applied engineering solutions such as drainage or hydraulic structures and especially arrangement of new soil layer [30].

\section{Conclusion}

Illegal dumping is a dangerous affair and puts people health and safety at risk, especially when hazardous chemicals are involved and can threat the environment by polluting land and water resources [31]. Illegal dumping is also dangerous for land owners who could be breaking the law by knowingly or unknowingly allowing waste to be dumped on their property without the necessary approvals [32-35]. Even if a land owner unwittingly allows 
waste to be dumped on their property it can still pollute land and water, and clean-up cost may be very expensive [36]. In this paper the method for reclamation of the polluted areas as the complex way is proposed. The problem urgency is considered. A step-by-step draft of land reclamation is offered, preliminary phase is considered attentively, the connection with the hydrophysical properties of the soil researches is approved, and the importance of them is founded. The technical and biological stages of case are also investigated, all researches are done for the example of the illegal dumping site in Sverdlovo of Leningrad Oblast', Russia.

Acknowledgements

The research was supported by DAAD (A/10/01103), DFG (MI 526/3-1) and Russian Foundation for Basic Research (\#16-04-01473-a).

\section{References}

1. Information on http://eco.lenobl.ru/programm/news?id=38660

2. V.I. Smetanin, Reclamation and improvement of disturbed lands, 94 (2003).

3. H. Ødegaard, Water Science and Technology, 53, 17-33 (2006)

4. A. Kholodiakov, A. Bondal, M. Zubkova, A. Chusov, Ability to use the methane component of the modern WWTP biogas as an alternative energy source: submitted to Materials Science Forum (2016)

5. H. Vereecken, M. Weynants, M. Javaux, Y. Pachepsky, M.G. Schaap, M.Th. Van Genuchten, Vadose Zone J., 9, 795-820 (2010)

6. V.V. Terleev, W. Mirschel, U. Schindler, K.-O. Wenkel, Estimation of soil water retention curve using some agrophysical characteristics and Voronin's empirical dependence, 381-387 (International Agrophysics 24, 2010)

7. Y. Mualem, Water Resour. Res., 12, 513-522 (1976)

8. M.Th. Van Genuchten, Soil Sci. Soc. Amer. J., 44, 892-989 (1980)

9. V. Terleev, V. Badenko, I. Guseva, W. Mirschel, Applied Mechanics and Materials, 725-726 (2015)

10. V. Terleev, A. Nikonorov, V. Badenko, I. Guseva, Yu. Volkova, O. Skvortsova, S. Pavlov, W. Mirschel, Advances in Civil Engineering, Article ID 8176728, 7 (2016) (doi:10.1155/2016/8176728)

11. L. Svatovskaya, A. Sychova, M. Sychov, V. Okrepilov, MATEC Web of Conferences, 53, Article Number 01023 (2016)

12. K. Kosugi, Water Resour. Res., 32, 2697-2703 (1996)

13. K. Kosugi, J.W. Hopmans, Soil Sci. Soc. Am. J., 62, 1496-1505 (1998)

14. K. Kosugi, Soil Sci. Soc. Am. J., 63, 270-277 (1999)

15. A.V. Motorina et al., Industrial and land reclamation, 240 (1975).

16. D.V. Gorlov, Land reclamation in the quarries, 260 (1981).

17. A.D. Gorbovskay, Ecology of soils, 170 (2015).

18. B. Baranova, P. Manko, T. Jaszay, Ecological Engineering, 81, 1-13 (2015)

19. N Arefiev, V. Terleev, V. Badenko, Procedia Engineering, 117, 39-44 (2015)

20. R.A. Poluektov, V.V. Terleev, Russian Meteorology and Hydrology, 11, 70-75 (2002)

21. R.A. Poluektov, V.V. Terleev, Russian Meteorology and Hydrology, 12, 73-77 (2005)

22. R.A. Poluektov, I.V. Oparina, V.V. Terleev, Russian Meteorology and Hydrology, 11, 61-67 (2003)

23. N. Arefiev, V. Badenko, A. Nikonorov, V. Terleev, Y. Volkova, Procedia Engineering, 117, 20-25 (2015)

24. A. Nikonorov, S. Pavlov, V. Terleev, N. Arefiev, V. Badenko, Y. Volkova, Use of Procedia Engineering, 117, 258-263 (2015) 
25. R.A. Poluektov, S.M. Fintushal, I.V. Oparina, D.V. Shatskikh, V.V. Terleev, E.T. Zakharova, Archives of Agronomy and Soil Science, 48, 609-635 (2002)

26. K.Ch. Kersebaum, J.-M. Hecker, W. Mirschel, M. Wegehenkel (Eds), Proceedings of the Workshop, Leibniz Centre of Agricultural Landscape Research (ZALF) in Müncheberg/Germany, 75-89 (2007)

27. V. Badenko, V. Terleev, A. Topaj, Applied Mechanics and Materials, 635-637 (2014)

28. S. Medvedev, A. Topaj, V. Badenko, V. Terleev, IFIP Advances in Information and Communication Technology, 448, 252-261 (2015)

29. V. Badenko, V. Terleev, N. Arefiev, J. Volkova, O. Nikonova, Proceedings of the AASRI International Conference on Industrial Electronics and Applications (IEA 2015). Book Series: AER-Advances in Engineering Research, 2, $452-455$ (2015)

30. V. Chechevichkin, N. Vatin, Applied Mechanics and Materials, 641-642 (2014)

31. M.G. Ryzhakova, V.I. Maslikov, A.N. Chusov, V.V. Korablev, Applied Mechanics and Materials, 675-677 (2014)

32. N. Seror, S. Hareli, B. Portnov, Waste Management, 34, 1436-1445 (2014)

33. K. Ishii, T. Furuichi, Y. Nagao, Waste Management, 33, 445-455 (2013)

34. D. Ichinose, M. Yamamoto, Resource and Energy Economics, 33, 79-93 (2011)

35. R. Chaubey, S. Sahu, O.O. James, S. Maity, Renewable and Sustainable Energy Reviews, 23, 443-462 (2013)

36. N. Arefiev, V. Garmanov, V. Bogdanov, Y. Ryabov, V. Terleev, V. Badenko, Procedia Engineering, 117, 26-31 (2015) 